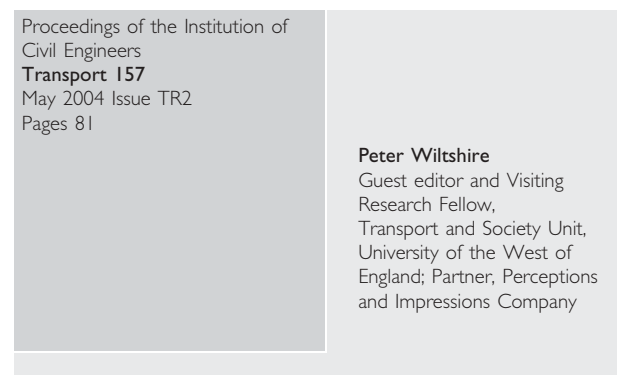

\title{
Editorial: A 'hot-house' of creative thinking
}

\section{P. J. Wiltshire}

The Editorial Panel has firmly resolved that Transport should offer a mix of papers covering detail and strategic topics. The decision was not lightly reached and one of the main reasons was that transport history records how detailed development and invention can seriously affect strategic planning.

Some time ago a few rude mechanicals were working on an extraordinary idea to place a steam engine in a moving vehicle. The consequence was not just a local change to transport, but a radical shift in social outlook across the entire world. Similarly, but to a lesser extent, the handheld computer has made it possible to enforce decriminalised parking control and therefore attitudes to car use in towns has changed; the mini-roundabout made it possible to accommodate much more traffic than had been expected; and poor standards of track maintenance have had a precipitous effect upon a nation's view of its transport policies.

Perhaps future generations will see the London Congestion Charging Scheme as the point in history when the free Western society accepted the idea of rationed travel. Next century, people might be allocated only 500 miles per week. The psycho-sociological effects of such restrictions could be of major political significance.

Over the past 50 years our own generation has been reasonably inventive and, arguably, society now benefits from radically improved travel opportunities. However, many of us are concerned that we are running out of solutions. In recognition of the problem, the four main professional bodies concerned came together in 1997 to create the Transport Planning Society. These bodies were:

- The Institution of Civil Engineers

- The Institute of Logistics and Transport

- The Royal Town Planning Institute

- The Institution of Highways and Transportation

The TPS has been a hot-house of creative thinking enabling cross-fertilization of ideas between the various professions involved. Eighteen months ago the Journal placed a small advertisement calling for papers and received a flood of interest. However, it takes time for papers to be written and for them to be assessed. But we are now seeing some of the results in this special edition.

A fairly consistent factor that is emerging is a tendency to look for solutions through social engineering rather than the construction of more capacity, recognising that we cannot cope with the demand for travel that our free society has produced. Measures like road pricing, travel awareness, demand management, tax increases and legal restraints have taken the place of a belief that we can build our way out of the difficulties. Infrastructure construction is still important to solve immediate or short-term problems but very few are prepared to put their faith in satisfying demand in the longer term by this action.

As a sub-set of the social engineering category of activity, transport and communications are now being perceived as linked activities and electronic advances in communications hold out significant hope for reducing travel demand in the future. A similar departure from traditional thought is the linking of transport to urban social structure and the lifestyle expectations therein, the sort of thought process that challenges the wisdom of related policies as, for example, parental choice for schooling.

The Editorial Panel is intending to maintain a high proportion of papers on transport planning in future issues. Several papers held over for lack of space this time will be included in later editions. To continue the theme of a broad mix of topics, more papers are welcomed and readers who would like to contribute should contact the Journal Secretary, Emma Holder, at emma.holder@ice.org.uk. Please also look through the Author Guidelines at the back of this publication.

For more information upon the activities of the ICE Transport Board go to <www.ice.org.uk/knowledge/specialist_transport.asp>

For information about the Transport Planning Society go to $<$ www.tps.org.uk $>$ 